\title{
Possible Association of SLC22A2 Polymorphisms with Aspirin-Intolerant Asthma
}

\author{
Tae-Joon Park ${ }^{a}$ Jeong-Hyun Kim ${ }^{a}$ Joon-Seol Bae ${ }^{a}$ Byung-Lae Park ${ }^{b}$ \\ Hyun Sub Cheong $^{\mathrm{b}} \quad$ Ji-Yong Chun $^{\mathrm{a}} \quad$ Jin-Sol Lee ${ }^{\mathrm{a}}$ Jason Yongha Kim ${ }^{\mathrm{a}}$ \\ Charisse Flerida Pasaje $^{a}$ Sang Heon Cho ${ }^{c}$ Soo-Taek Uh ${ }^{d}$ Mi-Kyeong Kim ${ }^{e}$ \\ Inseon S. Choi ${ }^{f}$ In Song Kohg Choon-Sik Park ${ }^{d}$ Hyoung Doo Shin ${ }^{a, b}$ \\ a Department of Life Science, Sogang University, ${ }^{\mathrm{b}}$ Department of Genetic Epidemiology, SNP Genetics, and \\ 'Department of Internal Medicine and Institute of Allergy and Clinical Immunology, Seoul National University \\ College of Medicine, Seoul, ${ }^{d}$ Genome Research Center for Allergy and Respiratory Diseases, Soonchunhyang \\ University Hospital, Buchon, ' Division of Internal Medicine, College of Medicine, Chungbuk National University, \\ Cheongju, ${ }^{f}$ Department of Allergy, Chonnam National University Medical School and Research Institute of Medical \\ Sciences, Gwangju, and ${ }^{9}$ Department of Physiology, College of Medicine, Han Yang University, Seoul, Republic of Korea
}

\section{Key Words}

Solute carrier family 22, member $2 \cdot$ Aspirin-intolerant asthma $\cdot$ Polymorphism $\cdot$ Haplotype

\begin{abstract}
Background: Aspirin-intolerant asthma (AIA) is a clinical syndrome characterized by acute bronchoconstriction following the ingestion of aspirin. Solute carrier family 22, member 2 (SLC22A2), also known as organic cation transporter 2 (OCT2), is predominantly expressed in the luminal membrane of airway epithelial cells and has been shown to mediate the transport of prostaglandins on the cyclooxygenase pathway which is regulated by aspirin blockage. Recently, SLC22A2-mediated uptake inhibition by several nonsteroidal anti-inflammatory drugs and decreased SLC22A2 transport activity by its genetic variants have been elucidated in asthma. Methods: To investigate the associations between AIA and genetic polymorphisms of the SLC22A2 gene,
\end{abstract}

\section{KARGER}

Fax +41613061234 E-Mail karger@karger.ch www.karger.com
(ㄷ) 2011 S. Karger AG, Basel

$1018-2438 / 11 / 1554-0395 \$ 38.00 / 0$

Accessible online at:

www.karger.com/iaa
18 variants were genotyped in 163 AIA subjects and 429 aspirin-tolerant asthma (ATA) controls. Logistic analyses were used to evaluate $p$ values for the associations of SLC22A2 polymorphisms with AIA. Results: One common polymorphism in intron 5, i.e. rs316021, was significantly associated with susceptibility to AIA ( $p=0.004$, $P^{c o r r}=0.05, O R=0.60$, $95 \% \mathrm{Cl}=0.43-0.85$ in a codominant model). The minor allele frequency of $r$ s 316021 in the AIA group was significantly lower than that in the ATA controls. In addition, a polymorphism in intron 4 (rs3912161) and a haplotype (SLC22A2-ht3) showed significantly stronger association signals with the $\mathrm{FEV}_{1}$ fall rate induced by aspirin provocation in AIA subjects compared with ATA controls $\left(p=0.004\right.$, $\left.p^{\text {corr }}=0.05\right)$. Conclusion: Our findings suggest that SLC22A2 could be a susceptibility gene for aspirin intolerance in asthmatics.

Copyright ๑ 2011 S. Karger AG, Basel

Correspondence to: Prof. Hyoung Doo Shin

Department of Life Science, Sogang University

Shinsu-dong

Seoul 121-742 (Republic of Korea)

Tel. +82 2705 8615, E-Mail hdshin@ sogang.ac.kr

Co-corresponding author: Dr. Choon-Sik Park

Genome Research Center for Allergy and Respiratory Diseases

Soonchunhyang University Hospital

Buchon, 420-767 (Republic of Korea)

Tel. +82 32621 5105, E-Mail mdcspark@unitel.co.kr 


\section{Introduction}

Aspirin-intolerant asthma (AIA) is a unique clinical syndrome characterized by acute bronchoconstriction following the ingestion of aspirin or other nonsteroidal anti-inflammatory drugs (NSAIDs). This syndrome is characterized by the triad of aspirin hypersensitivity, bronchial asthma, and chronic rhinosinusitis with nasal polyposis $[1,2]$. AIA affects $5-15 \%$ of asthmatics and occurs more frequently in women [3, 4]. A 2-compartment model that is composed of the augmentation of cysteinyl leukotriene (CysLT) production and the overexpression of the CysLT receptor on inflammatory cells within the respiratory tract has been proposed as a factor in the development of AIA. However, to date, the pathogenesis of AIA has not been clearly understood [5].

Human polyspecific solute carrier family 22 (organic cation transporter), member 2 (SLC22A2; MIM No. 602608), encoded by SLC22A2 is a member of the solute carrier family 22 superfamily, which constructs a structure consisting of 12 transmembrane domains. In previous studies, the transport of prostaglandins, which is converted from arachidonic acid in the cyclooxygenase pathway that is regulated by aspirin blockage, has been shown to be mediated by human organic cation transporters including SLC22A2 in the basolateral membrane of the proximal tubule [6]. Recently, it has also been revealed that polyspecific organic cation transports are involved in the transportation of acetylcholine $(\mathrm{ACh})$ as a novel regulator of airway remodeling $[7,8]$. Furthermore, SLC22A 2 has been elucidated to modulate ACh release in human bronchial epithelia [9], suggesting that SLC22A 2 might mediate the luminal release of $\mathrm{ACh}$ in human airways and that ingestion of NSAIDs could inhibit SLC22A2 functions in the treatment of asthma.

Based on these properties, we investigated whether single nucleotide polymorphisms (SNPs) of the SLC22A2 gene are associated with the risk of AIA.

\section{Materials and Methods}

\section{Study Subjects}

This study was conducted in compliance with the Global Initiative for Asthma (GINA) Global Strategy for Asthma Management and Prevention Study. Subjects were recruited from the Asthma Genome Research Center comprising the hospitals of Soonchunhyang, Chungnam, Chungbuk, and Seoul National Universities in Korea. All subjects provided their informed consent, and the protocols were approved by the Institutional Re- view Board of each hospital. Each patient showed airway reversibility measured by an inhalant bronchodilator-induced improvement of more than $15 \%$ in the forced expiratory volume in $1 \mathrm{~s}\left(\mathrm{FEV}_{1}\right)$ and/or a hyperresponsiveness of less than $10 \mathrm{mg} / \mathrm{ml}$ of PC20 methacholine [10]. A methacholine challenge test was performed 1 week before aspirin challenge. Oral aspirin challenge was performed in all asthmatic subjects with increasing doses of aspirin using methods that were slightly modified from those described previously [11]. Aspirin-induced bronchospasms presented by the rate (\%) of $\mathrm{FEV}_{1}$ decline were evaluated as the scores of the prechallenge $\mathrm{FEV}_{1}$ minus the postchallenge $\mathrm{FEV}_{1}$ divided by the prechallenge $\mathrm{FEV}_{1}$. Subjects showing a rate of $\mathrm{FEV}_{1}$ decline of less than $15 \%$ without naso-ocular or cutaneous reactions were included in the aspirin-tolerant asthma (ATA) group. Subjects with hypertension/diabetes or those taking angiotensin-converting enzyme inhibitors were excluded from this study. The clinical parameters are summarized in table 1 .

\section{SNP Selection and Genotyping}

We selected candidate SNPs that were reported to be nonmonomorphic in the National Center for Biotechnology Information (build 36), and then genotyped in 163 AIA and 429 ATA subjects. Genotyping was carried out using the Illumina GoldenGate genotyping system at a multiplex level [12], and data quality was evaluated via duplicate DNAs $(\mathrm{n}=10)$. The genotype quality score for retaining data was set to 0.25 . SNPs that were below the following standards were excluded: (i) a minimum call rate of $90 \%$, (ii) no duplicate error, and (iii) p values of Hardy-Weinberg equilibrium greater than 0.001. All 18 SNPs on SLC22A2 were successfully genotyped.

\section{Statistics}

Comparisons of genotype distributions between AIA and ATA subjects were carried out using logistic regression controlling for sex, smoking status, and atopy as covariates using HelixTree ${ }^{\circledR}$ software (Golden Helix, Bozeman, Mont., USA). To carry out the association analysis of the polymorphisms in SLC22A2, we examined Lewontin's D' $\left(\left|D^{\prime}\right|\right)$ and the linkage disequilibrium (LD) coefficient $r^{2}$ between all pairs of biallelic loci. LD was inferred using the algorithm developed by the Broad Institute (using the program Haploview) [13]. Haplotypes were first estimated using PHASE software [14] and then computed by logistic analyses using Statistical Analysis System (SAS). Subjects harboring missing genotypes were omitted in the analysis of individual SNPs and haplotypes. The genotyping success rate was $>99 \%$, with $0.7 \%$ missing genotypes; it is unlikely that omitting a small number of individuals introduced any bias into the analysis. Significant associations are shown in bold face $(p<0.05)$. The common alleles were used as the referent genotype to the heterozygote and homozygote of the minor allele in referent analysis. The effective numbers of independent marker loci in each gene were calculated to correct for multiple testing using the software SNPSpD (http://genepi.qimr.edu. $\mathrm{au} /$ general/daleN/SNPSpD/), which is based on the spectral decomposition $(\mathrm{SpD})$ of the matrices of pair-wise LD between SNPs [15]. 
Table 1. Clinical profiles of AIA patients and controls

\begin{tabular}{lccc}
\hline Clinical profile & $\begin{array}{l}\text { Asthmatics } \\
\text { (all subjects) }\end{array}$ & AIA & ATA \\
\hline $\mathrm{n}$ & 592 & 163 & 429 \\
Mean age of first medical examination (range), years & $46.15(15.40-77.88)$ & $43.13(17.22-72.73)^{*}$ & $47.30(15.40-77.88)$ \\
Height, cm & $160.78 \pm 8.63$ & $160.42 \pm 8.39$ \\
Weight, kg & $62.81 \pm 10.84$ & $61.25 \pm 10.38^{*}$ & $63.40 \pm 10.97$ \\
BMI & $24.24 \pm 3.39$ & $23.39 \pm 3.25^{*}$ & $3.54 \pm 4.85$ \\
Fall rate, \% & $9.27 \pm 13.24$ & $24.63 \pm 16.11^{* *}$ & $6.03 \pm 5.92$ \\
Blood eosinophil, \% & $6.01 \pm 5.73$ & $5.96 \pm 5.21$ & $87.85 \pm 14.05$ \\
FVC \% predicted & $88.54 \pm 14.08$ & $90.35 \pm 14.04$ & $91.66 \pm 16.87$ \\
FEV $\%$ predicted & $90.54 \pm 16.97$ & $87.58 \pm 16.94^{*}$ & $6.91 \pm 8.90$ \\
PC20, methacholine, mg/ml & $6.43 \pm 8.67$ & $5.02 \pm 7.83^{*}$ & $361.00 \pm 607.56$ \\
Total IgE, IU/ml & $357.65 \pm 604.09$ & $348.60 \pm 596.44$ & $147 / 282$ \\
Male/female ratio & $206 / 386$ & $59 / 104$ & 30.07 \\
Current smoker, \% & 27.70 & $21.47^{*}$ & 57.81 \\
Positive rate of skin test, \% & 56.42 & 52.76 & 35.75 \\
Positive rate of specific IgE, D.f., \% & 36.38 & 38.30 & 44.16 \\
Positive rate of specific IgE, D.p., \% & 44.56 & 45.77 & \\
\hline
\end{tabular}

Each clinical profile of AIA was compared to the respective ATA control. BMI = Body mass index; FVC = forced expiratory vital capacity; $\mathrm{FEV}_{1}=$ forced expiratory volume in $1 \mathrm{~s}$; D.f. = Dermatophagoides farinae; D.p. = Dermatophagoides pteronyssinus .

${ }^{*} \mathrm{p}<0.05,{ }^{* *} \mathrm{p}<0.0001$ compared to ATA control.

\section{Results}

\section{Characteristics of the Study Subjects}

The clinical profiles of the study subjects are summarized in table 1 . The asthmatic subjects were divided into 2 groups (AIA and ATA groups) according to their sensitivity to aspirin. A decrease in $\mathrm{FEV}_{1}$ of -15 to $68 \%$ induced by aspirin provocation was observed. The percentage of decrease in $\mathrm{FEV}_{1}$ by aspirin provocation in AIA patients was significantly higher compared to ATA controls $(\mathrm{p}<0.0001)$. The values of $\mathrm{FEV}_{1} \%$ predicted and PC20 methacholine were significantly lower in AIA patients than in ATA controls $(\mathrm{p}<0.05)$. The percentage of current smokers was significantly lower in the AIA group than in the ATA group $(\mathrm{p}<0.05)$. In addition, the mean age of patients who had their first medical examination was significantly lower in AIA patients than in ATA controls $(\mathrm{p}<0.05)$, indicating that the symptomatic outcome of AIA patients may occur earlier depending on the sensitivity to aspirin.

\section{Genotyping and Haplotypes Inferred}

We selected 18 nonmonomorphic sequence variants in the SLC22A 2 gene: 1 in the promoter (rs3127573), 1 in the coding region of exon 4 ( $r$ s316019), 3 in 3'-untranslated region ( $r s 9364550, r s 3127594$, and $r s 694812)$, and 13 in introns $(r s 316008$, rs3798156, rs316012, rs316013, rs316018, rs3912161, rs2279463, rs316021, rs315983, rs10945657, rs3798158, rs10755577, and $r s 13195185$ ) (online suppl. table 1, www.karger.com/doi/10.1159/000321267; fig. 1a). Eighteen SNPs were genotyped for the genetic association study with AIA. The minor allele frequencies of these 18 SNPs in a Korean population $(n=592)$ including 163 AIA and 429 ATA subjects are shown in online supplementary table 1 . The genotype distributions of all loci were in Hardy-Weinberg equilibrium ( $p>0.05)$. The LD coefficients $\left(\left|D^{\prime}\right|\right)$ among the SNPs were calculated for all of the study subjects (fig. 1c). Complete LDs were observed between SNPs, $r s 316012$ and $r s 316013$, rs316013 and $r s 316018$, and $r s 13195185$ and $r s 694812\left(r^{2}=1\right)$. Ten haplotypes were constructed, and 4 of these with frequencies over 0.05 (SLC22A2-ht1, SLC22A2-ht2, $S L C 22 A 2-h t 3$, and SLC22A2-ht4) were analyzed for the association study (table 2; fig. 1b).

\section{Associations of Polymorphisms and Haplotypes in SLC22A2 with AIA}

Eighteen SNPs and 4 haplotypes were analyzed for association with the risk of AIA using multiple logistic models in asthmatics (table 2). The association 

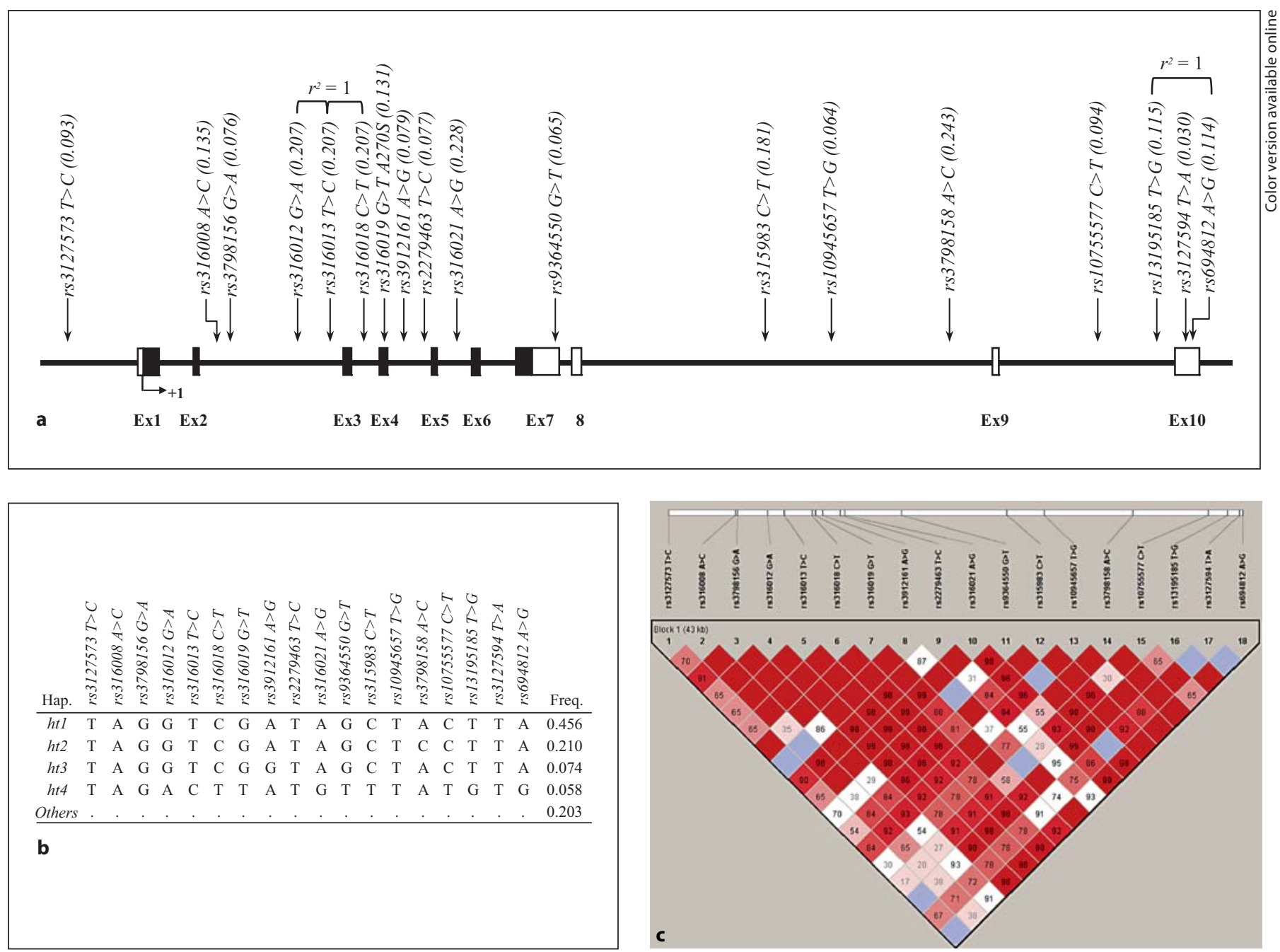

Fig. 1. Gene maps and haplotypes of the SLC22A2 gene. a Polymorphisms identified in SLC22A2. Coding exons are marked by black blocks and 3'-UTR by white blocks. The LD coefficients $\left(r^{2}\right)$ are based on the genotypes of Korean samples. b Haplotypes of SLC22A2 in the Korean population. Only those with frequencies over 0.01 are shown. c LD blocks and correlation coefficients among SLC22A2 polymorphisms. Hap. = Haplotype; Freq. $=$ frequency.

analyses showed that 1 SNP (rs3912161) and 1 haplotype (SLC22A2-ht3) were frequent in AIA subjects with a significant association of susceptibility with the risk of AIA, whereas 9 SNPs (rs316012, rs316013, rs316018, rs316021, rs9364550, rs315983, rs10755577, rs13195185, and rs694812) and 1 haplotype (SLC22A2-ht4) in AIA subjects showed considerably lower major allele frequencies (MAFs) than those in ATA controls. Specifically, rs316021 had the strongest genetic effect among the SNPs and showed an association with the risk of AIA after multiple testing corrections $\left(\mathrm{p}=0.004, P^{\text {corr }}=0.05, \mathrm{OR}=0.60,95 \% \mathrm{CI}=\right.$
$0.43-0.85$ in the codominant model) with a lower MAF in AIA patients compared to ATA controls ( $\mathrm{MAF}=0.172$ for AIA vs. 0.245 for ATA). When running multiple testing corrections on $\mathrm{p}$ values, the effective number of independent marker loci in SLC22A2 calculated by SNPSpD was 13.00 .

\section{Association of Polymorphisms and Haplotypes in} SLC22A2 with a Decline in FEV

In addition, we investigated the associations of the percentages of maximum $\mathrm{FEV}_{1}$ fall following aspirin 
Table 2. Analyses of association of SLC22A2 polymorphisms with risk of aspirin intolerance in asthma

\begin{tabular}{|c|c|c|c|c|c|c|c|c|c|c|c|c|c|}
\hline \multirow{2}{*}{$\begin{array}{l}\text { SNP/ } \\
\text { haplotype }\end{array}$} & \multirow[t]{2}{*}{ Allele } & \multirow[t]{2}{*}{ Position } & \multicolumn{2}{|l|}{ MAF } & \multicolumn{3}{|l|}{ Codominant } & \multicolumn{3}{|l|}{ Dominant } & \multicolumn{3}{|l|}{ Recessive } \\
\hline & & & $\begin{array}{l}\text { AIA } \\
(\mathrm{n}=163)\end{array}$ & $\begin{array}{l}\text { ATA } \\
(\mathrm{n}=429)\end{array}$ & OR (95\% CI) & $\mathrm{p}$ & $P^{\text {corr } *}$ & OR $(95 \% \mathrm{CI})$ & $\mathrm{p}$ & $P^{\text {corr } *}$ & OR (95\% CI) & $\mathrm{p}$ & $P^{\text {corr } *}$ \\
\hline$r s 3127573$ & $\mathrm{~T}>\mathrm{C}$ & Promoter & 0.087 & 0.097 & $0.91(0.57-1.43)$ & 0.67 & - & $0.91(0.56-1.48)$ & 0.71 & - & $0.67(0.07-6.15)$ & 0.72 & - \\
\hline rs316008 & $\mathrm{A}>\mathrm{C}$ & Intron2 & 0.114 & 0.142 & $0.73(0.49-1.10)$ & 0.14 & - & $0.70(0.45-1.08)$ & 0.10 & - & $1.23(0.20-7.57)$ & 0.83 & - \\
\hline rs3798156 & $\mathrm{G}>\mathrm{A}$ & Intron2 & 0.060 & 0.083 & $0.69(0.40-1.17)$ & 0.16 & - & $0.70(0.41-1.21)$ & 0.20 & - & - & 0.98 & - \\
\hline$r s 316012$ & $\mathrm{G}>\mathrm{A}$ & Intron2 & 0.163 & 0.221 & $0.66(0.47-0.93)$ & 0.02 & 0.23 & $0.63(0.43-0.93)$ & 0.02 & 0.27 & $0.52(0.17-1.57)$ & 0.25 & - \\
\hline rs316013 & $\mathrm{T}>\mathrm{C}$ & Intron2 & 0.163 & 0.222 & $0.66(0.47-0.93)$ & 0.02 & 0.22 & $0.63(0.43-0.93)$ & 0.02 & 0.25 & $0.52(0.17-1.57)$ & 0.24 & - \\
\hline rs316018 & $\mathrm{C}>\mathrm{T}$ & Intron3 & 0.163 & 0.221 & $0.66(0.47-0.93)$ & 0.02 & 0.23 & $0.63(0.43-0.93)$ & 0.02 & 0.27 & $0.52(0.17-1.57)$ & 0.25 & - \\
\hline rs316019 & $\mathrm{G}>\mathrm{T}$ & Exon4 & 0.102 & 0.139 & $0.70(0.46-1.05)$ & 0.08 & - & $0.71(0.45-1.11)$ & 0.13 & - & $0.27(0.03-2.09)$ & 0.21 & - \\
\hline rs3912161 & $\mathrm{A}>\mathrm{G}$ & Intron4 & 0.109 & 0.069 & $1.74(1.10-2.75)$ & 0.02 & 0.22 & $1.76(1.10-2.82)$ & 0.02 & 0.25 & $3.11(0.17-57.14)$ & 0.44 & - \\
\hline$r s 2279463$ & $\mathrm{~T}>\mathrm{C}$ & Intron4 & 0.063 & 0.083 & $0.72(0.43-1.22)$ & 0.22 & - & $0.74(0.43-1.26)$ & 0.27 & - & - & 0.98 & - \\
\hline rs316021 & $\mathrm{A}>\mathrm{G}$ & Intron5 & 0.172 & 0.245 & $0.60(0.43-0.85)$ & 0.004 & 0.05 & $0.57(0.39-0.84)$ & 0.005 & 0.06 & $0.45(0.15-1.35)$ & 0.15 & - \\
\hline$r s 9364550$ & $\mathrm{G}>\mathrm{T}$ & 3'-UTR & 0.036 & 0.075 & $0.49(0.26-0.92)$ & 0.03 & 0.34 & $0.49(0.26-0.94)$ & 0.03 & 0.42 & - & 0.98 & - \\
\hline$r s 315983$ & $\mathrm{C}>\mathrm{T}$ & Intron8 & 0.139 & 0.192 & $0.63(0.43-0.91)$ & 0.01 & 0.19 & $0.59(0.39-0.89)$ & 0.01 & 0.14 & $0.70(0.19-2.59)$ & 0.59 & - \\
\hline rs10945657 & $\mathrm{T}>\mathrm{G}$ & Intron8 & 0.054 & 0.066 & $0.74(0.42-1.32)$ & 0.31 & - & $0.74(0.42-1.32)$ & 0.31 & - & - & - & - \\
\hline rs3798158 & $\mathrm{A}>\mathrm{C}$ & Intron 8 & 0.262 & 0.245 & $1.10(0.82-1.48)$ & 0.52 & - & $1.09(0.75-1.57)$ & 0.66 & - & $1.31(0.65-2.65)$ & 0.46 & - \\
\hline rs10755577 & $\mathrm{C}>\mathrm{T}$ & Intron9 & 0.063 & 0.103 & $0.59(0.36-0.98)$ & 0.04 & 0.54 & $0.61(0.36-1.03)$ & 0.06 & 0.82 & - & 0.98 & - \\
\hline rs13195185 & $\mathrm{T}>\mathrm{G}$ & Intron9 & 0.084 & 0.124 & $0.63(0.40-0.99)$ & 0.04 & 0.57 & $0.61(0.38-0.99)$ & 0.04 & 0.58 & $0.47(0.06-3.92)$ & 0.48 & - \\
\hline$r s 3127594$ & $\mathrm{~T}>\mathrm{A}$ & $3^{\prime}$-UTR & 0.027 & 0.029 & $0.90(0.41-2.00)$ & 0.80 & - & $0.90(0.41-2.00)$ & 0.80 & - & - & - & - \\
\hline$r s 694812$ & $\mathrm{~A}>\mathrm{G}$ & 3'-UTR & 0.084 & 0.121 & $0.64(0.41-1.00)$ & 0.05 & 0.67 & $0.62(0.39-1.00)$ & 0.05 & 0.65 & $0.57(0.07-4.92)$ & 0.61 & - \\
\hline SLC22A2-ht1 & & & 0.443 & 0.452 & $0.96(0.75-1.25)$ & 0.78 & - & $0.88(0.60-1.30)$ & 0.53 & - & $1.06(0.67-1.65)$ & 0.81 & - \\
\hline SLC22A2-ht2 & & & 0.232 & 0.210 & $1.15(0.84-1.57)$ & 0.39 & - & $1.13(0.78-1.65)$ & 0.51 & - & $1.45(0.61-3.41)$ & 0.40 & - \\
\hline SLC22A2-ht3 & & & 0.102 & 0.063 & $1.79(1.12-2.87)$ & 0.01 & 0.19 & $1.81(1.12-2.95)$ & 0.02 & 0.21 & $3.13(0.17-57.20)$ & 0.44 & - \\
\hline SLC22A2-ht4 & & & 0.033 & 0.065 & $0.50(0.26-0.97)$ & 0.04 & 0.51 & $0.50(0.25-0.99)$ & 0.05 & 0.62 & - & 0.99 & - \\
\hline
\end{tabular}

Logistic models adjusted for age, sex, smoking status, and atopy as covariates were used. Bold values indicate the case of $\mathrm{p}<0.05$.

* p values after correction for multiple testing.

provocation with genotypes or haplotypes using multiple linear regression analyses (table 3). Ten SNPs ( $r s 316012$, $r s 316013, \quad r s 316018, \quad r s 3912161, \quad r s 316021, \quad r s 9364550$, rs315983, rs10755577, rs13195185, and $r s 694812)$ were significantly associated with the percentage of maximum $\mathrm{FEV}_{1}$ fall induced by aspirin provocation in asthmatics before multiple testing corrections, with the strongest significance in rs3912161. However, no SNP showed a nominal association signal after multiple testing corrections among these 10 SNPs. Asthmatics who carried minor allele $r s 3912161$ exhibited a significantly higher fall rate of $\mathrm{FEV}_{1}$ induced by aspirin provocation than that of those who carried the major allele. In the haplotype analysis, SLC22A2-ht3 containing the minor allele rs3912161 was also significantly associated with the percentage of maximum $\mathrm{FEV}_{1}$ fall induced by aspirin challenge in the asthmatics $\left(\mathrm{p}=0.004\right.$, $P^{\text {corr }}=0.05$ in the codominant model). The asthmatics with SLC22A2-ht3 homozygotes had the highest responses to aspirin challenge, whereas those with SLC22A 2-ht4 homozygotes showed the lowest responses.

\section{Discussion}

AIA is an allergic reaction caused by the administration of aspirin [4]. It is characterized by acetyl salicylic acid hypersensitivity, bronchial asthma, and chronic rhinosinusitis with nasal polyposis [16]. Although many AIA susceptible genetic variants have been reported on 5-lipoxygenase and leukotriene synthetic pathways, a comprehensive etiology of AIA has not been clearly identified to date; thus, there is a need for new links to airway remodeling in the pathogenesis of AIA. Therefore, our findings on the associations between genetic polymorphisms and their haplotypes in the SLC22A2 gene and AIA provide a new link between organic cation transportation and aspirin hypersensitivity in asthmatics, with a possible involvement of ACh as a novel regulator of airway remodeling.

Among the 10 SNPs and 2 haplotypes associated with AIA in this study, rs316021, which is located in the intronic region, showed a potential association signal with the risk of AIA after multiple testing corrections $(\mathrm{p}=0.004$, $\left.P^{\text {corr }}=0.05, \mathrm{OR}=0.60,95 \% \mathrm{CI}=0.43-0.85\right)$. The result is meaningful since introns can affect the transcription efficiency of genes, which in turn may affect gene expres- 
Table 3. Regression analysis for the association of SNPs and haplotypes of the $S L C 22 \mathrm{~A} 2$ gene with the maximum fall rate of FEV $\mathrm{b}_{1}$ aspirin provocation in asthmatics

\begin{tabular}{|c|c|c|c|c|c|c|c|c|c|c|}
\hline \multirow{2}{*}{$\begin{array}{l}\text { SNP/ } \\
\text { haplotype }\end{array}$} & \multirow[t]{2}{*}{ Allele } & \multicolumn{3}{|l|}{ Genotype } & \multicolumn{2}{|c|}{ Codominant } & \multicolumn{2}{|c|}{ Dominant } & \multicolumn{2}{|c|}{ Recessive } \\
\hline & & $\mathrm{C} / \mathrm{C}$ & $\mathrm{C} / \mathrm{R}$ & $\mathrm{R} / \mathrm{R}$ & $\mathrm{p}^{*}$ & $P^{\text {corr } * *}$ & $\mathrm{p}^{*}$ & $P^{\text {corr } * *}$ & $\mathrm{p}^{*}$ & $P^{\text {corr ** }}$ \\
\hline$r s 3127573$ & $\mathrm{~T}>\mathrm{C}$ & $487(9.48 \pm 13.40)$ & $101(8.17 \pm 12.54)$ & $4(5.63 \pm 4.50)$ & 0.32 & - & 0.35 & - & 0.57 & - \\
\hline$r s 316008$ & $A>C$ & $438(9.70 \pm 13.65)$ & $149(7.80 \pm 11.64)$ & $5(11.00 \pm 18.51)$ & 0.17 & - & 0.15 & - & 0.97 & - \\
\hline$r s 3798156$ & $\mathrm{G}>\mathrm{A}$ & $504(9.45 \pm 13.27)$ & $86(8.06 \pm 13.04)$ & $2(5.50 \pm 7.78)$ & 0.33 & - & 0.36 & - & 0.62 & - \\
\hline$r s 316012$ & $\mathrm{G}>\mathrm{A}$ & $372(10.12 \pm 14.16)$ & $197(7.74 \pm 11.59)$ & $23(7.67 \pm 9.03)$ & 0.04 & 0.56 & 0.03 & 0.42 & 0.58 & - \\
\hline rs316013 & $\mathrm{T}>\mathrm{C}$ & $371(10.13 \pm 14.18)$ & $197(7.74 \pm 11.59)$ & $23(7.67 \pm 9.03)$ & 0.04 & 0.55 & 0.03 & 0.41 & 0.58 & - \\
\hline rs316018 & $\mathrm{C}>\mathrm{T}$ & $372(10.12 \pm 14.16)$ & $197(7.74 \pm 11.59)$ & $23(7.67 \pm 9.03)$ & 0.04 & 0.56 & 0.03 & 0.42 & 0.58 & - \\
\hline$r s 316019$ & $\mathrm{G}>\mathrm{T}$ & $451(9.73 \pm 13.97)$ & $129(7.71 \pm 10.74)$ & $12(7.01 \pm 4.89)$ & 0.10 & & 0.09 & & 0.68 & - \\
\hline$r s 3912161$ & $A>G$ & $499(8.62 \pm 12.24)$ & $90(12.02 \pm 17.00)$ & $2(32.00 \pm 29.70)$ & 0.004 & 0.05 & 0.01 & 0.13 & 0.01 & 0.15 \\
\hline rs 2279463 & $\mathrm{~T}>\mathrm{C}$ & $503(9.42 \pm 13.27)$ & $87(8.26 \pm 13.09)$ & $2(5.50 \pm 7.78)$ & 0.40 & - & 0.43 & - & 0.62 & - \\
\hline$r s 316021$ & $A>G$ & $352(10.21 \pm 14.13)$ & $214(7.84 \pm 11.98)$ & $26(7.48 \pm 8.59)$ & 0.03 & 0.42 & 0.02 & 0.30 & 0.55 & - \\
\hline rs9364550 & $\mathrm{G}>\mathrm{T}$ & $520(9.66 \pm 13.74)$ & $68(6.23 \pm 8.22)$ & $4(5.28 \pm 1.81)$ & 0.05 & 0.66 & 0.05 & 0.60 & 0.62 & - \\
\hline$r s 315983$ & $\mathrm{C}>\mathrm{T}$ & $395(10.12 \pm 13.91)$ & $184(7.31 \pm 11.58)$ & $13(9.41 \pm 11.36)$ & 0.03 & 0.37 & 0.02 & 0.21 & 0.94 & - \\
\hline rs10945657 & $\mathrm{T}>\mathrm{G}$ & $518(9.27 \pm 12.97)$ & $74(9.00 \pm 14.92)$ & - & 0.74 & - & 0.74 & - & - & - \\
\hline$r s 3798158$ & $A>C$ & $337(9.53 \pm 13.22)$ & $217(8.78 \pm 13.04)$ & $38(9.19 \pm 14.44)$ & 0.64 & - & 0.58 & - & 0.95 & - \\
\hline rs 10755577 & $\mathrm{C}>\mathrm{T}$ & $487(9.82 \pm 13.75)$ & $99(6.59 \pm 10.33)$ & $5(5.80 \pm 3.64)$ & 0.03 & 0.35 & 0.03 & 0.33 & 0.55 & - \\
\hline rs13195185 & $\mathrm{T}>\mathrm{G}$ & $465(9.90 \pm 14.03)$ & $120(6.71 \pm 9.52)$ & $7(7.94 \pm 5.93)$ & 0.02 & 0.32 & 0.02 & 0.21 & 0.86 & - \\
\hline$r s 3127594$ & $\mathrm{~T}>\mathrm{A}$ & $558(9.35 \pm 13.21)$ & $34(7.36 \pm 13.46)$ & - & 0.35 & - & 0.35 & - & - & - \\
\hline \multirow[t]{2}{*}{ rs694812 } & $A>G$ & $465(9.90 \pm 14.03)$ & $120(6.71 \pm 9.52)$ & $6(8.27 \pm 6.43)$ & 0.02 & 0.32 & 0.02 & 0.22 & 0.90 & - \\
\hline & & $-1-$ & $+/-$ & $+/+$ & & & & & & \\
\hline SLC22A2-ht1 & & $182(9.49 \pm 13.99)$ & $285(8.58 \pm 12.58)$ & $125(10.36 \pm 13.52)$ & 0.71 & - & 0.66 & - & 0.25 & - \\
\hline SLC22A2-ht2 & & $362(9.50 \pm 13.30)$ & $205(8.49 \pm 12.67)$ & $25(11.52 \pm 16.37)$ & 0.88 & - & 0.59 & - & 0.38 & - \\
\hline SLC22A2-ht3 & & $507(8.68 \pm 12.25)$ & $83(12.06 \pm 17.33)$ & $2(32.00 \pm 29.70)$ & 0.004 & 0.05 & 0.01 & 0.14 & 0.01 & 0.15 \\
\hline SLC22A2-ht4 & & $528(9.60 \pm 13.67)$ & $61(6.23 \pm 8.32)$ & $3(5.20 \pm 2.21)$ & 0.05 & 0.71 & 0.05 & 0.65 & 0.67 & - \\
\hline
\end{tabular}

The genotype distribution of each SNP is presented as the number of subjects. Data in parentheses indicate the percentage of $\mathrm{FEV}_{1}$ fall by aspirin provocation (mean $\pm \mathrm{SE}$ ). Bold values indicate the case of $\mathrm{p}<0.05$.

* $\mathrm{p}$ values for linear regression analysis controlling age, sex, smoking status, and atopy as covariates.

${ }^{* *} \mathrm{p}$ values after correction for multiple testing.

sion. A previous study described the effect of introns on the rate of transcription of genes through experiments using transgenic mice [17], whereas another report showed that splicing affecting genomic variants can lead to splicing abnormalities causing human disease phenotypes, e.g. exon skipping, activation of cryptic splice sites, or alteration of the fine balance of the alternatively spliced isoforms that are produced [18]. It has also been reported that an intronic polymorphism ( $r$ s3733072) in the interleukin-17 receptor B $(I L-17 R B)$ gene is associated with the risk of asthma [19]. Thus, it is possible that $r s 316021$ is involved in the onset of AIA by affecting the transcription process of the SLC22A2 gene. However, when comparing the lower minor allele frequency of $r s 316021$ in AIA patients $(\mathrm{MAF}=0.172)$ to that in ATA controls (MAF = 0.245 ), we do not rule out a possible protective effect of the variant since haplotype SLC22A2-ht3 with the major A allele is more frequent in AIA patients than in ATA controls and has a more significant association with AIA compared to SLC22A2-ht4 with the minor G allele.
SLC22A2 is a polyspecific solute carrier that mediates the luminal release of ACh, which has recently been recognized as a novel regulator of airway remodeling and serves as a neurotransmitter of the central and peripheral neurons in human airways $[8,9]$. Although ACh has been known as a typical neurotransmitter in the central and peripheral nervous systems and is synthesized from acetylcoenzyme A and choline by actyltransferase, it is also one of the strongest bronchoconstrictors that plays an important role in the regulation of airway function, specifically during airway wall remodeling in disease and immunomodulation $[20,21]$. The release of acetylcholine from bronchial epithelial cells mediates bronchoconstriction following the release of serotonin from mast cells. In addition, airway epithelial cells possess various muscarinic receptors that serve as potential targets of locally released $\mathrm{ACh}$, and dysregulation of these receptors in airway epithelial cells is a major cause of asthma [20, 21]. Despite no direct evidence correlating the genetic variations of SLC22A2 to an altered responsiveness to 
cholinergic stimulation, the modest significant associations of SLC22A3 polymorphisms with methamphetamine dependence, which is also related to cholinergic transmission, and polysubstance use in metamphetamine dependence have been recently reported [22]. Aspirin-induced bronchospasm following the inhalation of NSAIDs in aspirin-intolerant asthmatics with genetic polymorphisms of SLC22A2, therefore, could be related to the regulation of acetylcholine release from bronchial cells via altered SLC22A2 functions.

The transporter activities of Madin-Darby canine kidney cells that are overexpressed in the human SLC22A2 variants (Thr199Ileu, Thr201Met, and Ala270Ser) showed a significantly decreased uptake of $\left[{ }^{3} \mathrm{H}\right]$ methyl-4-phenylpyridinium acetate $\left(\mathrm{MPP}^{+}\right)$or $\left[{ }^{14} \mathrm{C}\right]$ tetraethylammonium (TEA) compared with cells that are overexpressed in the wild-type SLC22A2 [23]. It has been shown that TEA plays a role in the increase of vital capacity among bronchial asthma patients [24] and significantly decreases the relaxant effects of propofol on ovalbumin-induced asthma in guinea pigs [25]. From these results, we suspect that the 3 SLC22A2 SNPs (Thr199Ileu, Thr201Met, and Ala270Ser) mentioned above are involved in the development of bronchial asthma which results from a reduced vital capacity caused by a decrease in the transport of TEA. A previous study revealed an association between the SLC22A2 polymorphism and other human diseases. It has been shown that the Ala270Ser polymorphism in the SLC22A2 gene is significantly associated with systemic arterial hypertension in the Caucasian population. $\mathrm{Pa}-$ tients who possessed the Ser270 allele were less frequent- ly affected by the clinical diagnosis of hypertension than were homozygote carriers of the wild-type allele Ala270 [26]. In this study, the Ala270Ser polymorphism (rs316019) was also identified and analyzed for its association with AIA; however, we were not able to establish a significant association between this polymorphism and AIA.

In conclusion, we identified 18 genetic variants in the human SLC22A2 gene. All of the polymorphisms were selected for genotyping in our asthma cohort association study, and statistical analyses revealed that $r s 316021$ was significantly associated with the risk of AIA and that rs3912161 and SLC22A2-ht3 were significantly associated with the maximum fall of FEV $\mathrm{F}_{1}$. Further studies on this gene including functional and replication studies elsewhere are needed to identify the roles of polymorphisms. These findings on the SLC22A2 gene may provide useful information in the development of new methods for the diagnosis of aspirin intolerance, as well as new strategies for the control of this asthma phenotype.

\section{Acknowledgements}

This work was supported by a grant from the Korea Health 21 R\&D Project (A010249); grant number M1-0302-00-0073 from the Korea Science and Engineering Foundation (KOSEF) funded by the Korean government (MEST) (No. 2009-0080157); an Intramural Research Grant from the Korea National Institute of Health (No. 4800-4845-300-260-00); an Intramural Research Grant from Sogang University (No. 200810021.01), and a Priority Research Centers Program through the National Research Foundation of Korea (NRF) funded by the Ministry of Education, Science, and Technology (2009-0093822).

\section{References}

1 Szczeklik A, Stevenson DD: Aspirin-induced asthma: advances in pathogenesis, diagnosis, and management. J Allergy Clin Immunol 2003;111:913-921, quiz 922.

2 Kowalski ML: Aspirin-sensitive rhinosinusitis and asthma. Clin Allergy Immunol 2007; 19:147-175.

-3 Babu KS, Salvi SS: Aspirin and asthma. Chest 2000;118:1470-1476.

4 Palikhe NS, Kim SH, Park HS: What do we know about the genetics of aspirin intolerance? J Clin Pharm Ther 2008;33:465-472.

5 Park JS, Chang HS, Park CS, Lee JH, Lee YM, Choi JH, Park HS, Kim LH, Park BL, Choi $\mathrm{YH}$, Shin HD: Association analysis of cysteinyl-leukotriene receptor 2 (CYSLTR2) polymorphisms with aspirin intolerance in asthmatics. Pharmacogenet Genomics 2005;15: 483-492.
6 Kimura H, Takeda M, Narikawa S, Enomoto A, Ichida K, Endou H: Human organic anion transporters and human organic cation transporters mediate renal transport of prostaglandins. J Pharmacol Exp Ther 2002; 301:293-298.

7 Wessler I, Roth E, Deutsch C, Brockerhoff P, Bittinger F, Kirkpatrick CJ, Kilbinger H: Release of non-neuronal acetylcholine from the isolated human placenta is mediated by organic cation transporters. Br J Pharmacol 2001;134:951-956.

8 Gosens R, Zaagsma J, Grootte Bromhaar M, Nelemans A, Meurs H: Acetylcholine: a novel regulator of airway smooth muscle remodelling? Eur J Pharmacol 2004;500:193-201.
9 Lips KS, Volk C, Schmitt BM, Pfeil U, Arndt P, Miska D, Ermert L, Kummer W, Koepsell $\mathrm{H}$ : Polyspecific cation transporters mediate luminal release of acetylcholine from bronchial epithelium. Am J Respir Cell Mol Biol 2005;33:79-88

10 Crapo RO, Casaburi R, Coates AL, Enright PL, Hankinson JL, Irvin CG, MacIntyre NR, McKay RT, Wanger JS, Anderson SD, Cockcroft DW, Fish JE, Sterk PJ: Guidelines for methacholine and exercise challenge testing - 1999: this official statement of the American Thoracic Society was adopted by the ATS Board of Directors, July 1999. Am J Respir Crit Care Med 2000;161:309-329.

-11 Cormican LJ, Farooque S, Altmann DR, Lee $\mathrm{TH}$ : Improvements in an oral aspirin challenge protocol for the diagnosis of aspirin hypersensitivity. Clin Exp Allergy 2005;35: 717-722. 
-12 Oliphant A, Barker DL, Stuelpnagel JR, Chee MS: BeadArray technology: enabling an accurate, cost-effective approach to highthroughput genotyping. Biotechniques 2002(suppl):56-58, 60-61.

13 Barrett JC, Fry B, Maller J, Daly MJ: Haploview: analysis and visualization of $\mathrm{LD}$ and haplotype maps. Bioinformatics 2005;21: 263-265.

14 Stephens M, Smith NJ, Donnelly P: A new statistical method for haplotype reconstruction from population data. Am J Hum Genet 2001;68:978-989.

-15 Nyholt DR: A simple correction for multiple testing for single-nucleotide polymorphisms in linkage disequilibrium with each other. Am J Hum Genet 2004;74:765-769.

16 Samter M, Beers RF Jr: Concerning the nature of intolerance to aspirin. J Allergy 1967; 40:281-293.

-17 Brinster RL, Allen JM, Behringer RR, Gelinas RE, Palmiter RD: Introns increase transcriptional efficiency in transgenic mice. Proc Natl Acad Sci USA 1988;85:836-840.
8 Pagani F, Baralle FE: Genomic variants in exons and introns: identifying the splicing spoilers. Nat Rev Genet 2004;5:389-396.

19 Jung JS, Park BL, Cheong HS, Bae JS, Kim JH, Chang HS, Rhim T, Park JS, Jang AS, Lee YM, Kim KU, Uh ST, Na JO, Kim YH, Park CS, Shin HD: Association of IL-17RB gene polymorphism with asthma. Chest 2009; 135:1173-1180.

20 Fujii T, Takada-Takatori Y, Kawashima K: Basic and clinical aspects of non-neuronal acetylcholine: expression of an independent, non-neuronal cholinergic system in lymphocytes and its clinical significance in immunotherapy. J Pharmacol Sci 2008;106:186192.

-21 Kummer W, Lips KS, Pfeil U: The epithelial cholinergic system of the airways. Histochem Cell Biol 2008;130:219-234.

22 Aoyama N, Takahashi N, Kitaichi K, Ishihara R, Saito S, Maeno N, Ji X, Takagi K, Sekine $\mathrm{Y}$, Iyo $\mathrm{M}$, Harano $\mathrm{M}$, Komiyama $\mathrm{T}$, Yamada M, Sora I, Ujike H, Iwata N, Inada T, Ozaki N: Association between gene polymorphisms of SLC22A3 and methamphetamine use disorder. Alcohol Clin Exp Res 2006;30:1644-1649.
23 Kang HJ, Song IS, Shin HJ, Kim WY, Lee CH, Shim JC, Zhou HH, Lee SS, Shin JG: Identification and functional characterization of genetic variants of human organic cation transporters in a Korean population. Drug Metab Dispos 2007;35:667-675.

24 Gregory L, Damiani M, Johanson M, Ormsby A, Ruskin A: Experiences with tetraethyl ammonium chloride in bronchial asthma. Dis Chest 1953;24:655-662.

25 Bagcivan I, Cevit O, Yildirim MK, Gursoy S, Yildirim S, Kaya T, Mimaroglu C: Investigation of the relaxant effects of propofol on ovalbumin-induced asthma in guinea pigs. Eur J Anaesthesiol 2007;24:796-802.

-26 Lazar A, Zimmermann T, Koch W, Grundemann D, Schomig A, Kastrati A, Schomig E: Lower prevalence of the OCT2 Ser270 allele in patients with essential hypertension. Clin Exp Hypertens 2006;28:645-653. 